\title{
lists of new members
}

The Council has approved the election of the following candidates to the grade of Member.

$\begin{array}{ll}\text { Almakaleh, Abdo A. } & \text { Deininger, Richard C. } \\ \text { Banta, Robert M. } & \text { Deshler, Terry L. } \\ \text { Baranowski, Gary A. } & \text { Dryden, Victor D. } \\ \text { Barnes, Jeffrey R. } & \text { Finfrock, David W. } \\ \text { Bartels, Diana L. } & \text { Franklin, Dee A. } \\ \text { Beard, Daniel W. } & \text { Gent, Peter R. } \\ \text { Bell, Brian P. } & \text { Haase, Sabine P. } \\ \text { Berka, Thomas S. } & \text { Helminen, Jaako A. U. } \\ \text { Black, James F. } & \text { Hoel, Doris D. } \\ \text { Blewitt, Doug N. } & \text { Horel, John D. } \\ \text { Boyd, Harry W. } & \text { Horsley, A. Doyne } \\ \text { Byrne, H. Michael } & \text { Hwang, Paul A. } \\ \text { Carton, James A. } & \text { Inoue, Masamichi } \\ \text { Chandler, Wayne P. } & \text { Kandel, Robert S. } \\ \text { Connors, Vickie S. } & \text { Keen, Kevin J. } \\ \text { Corio, Louis A. } & \text { Kim, Jongsoo } \\ \text { Covey, Curtis C. } & \text { Koziana, James V. } \\ \text { Daniels, James A. } & \text { Kwok-Wai, Kenneth L. } \\ \text { Davidson, Arthur } & \text { Lambeth, James D. } \\ \text { Dea, Jack Y. } & \text { Lamich, David J. } \\ \text { De Almeida Teixeira, Maria E. F. } & \text { Lanicci, John M. }\end{array}$

\author{
Lieberman, Ruth S. \\ London, Wendy B. \\ Low-Nam, Simon V. \\ Martinson, Douglas G. \\ Matari, Eliakim E. \\ McDougall, Trevor J. \\ McMurdie, Lynn A. \\ Michelsen, Dennis R. \\ Miller, David T. \\ Milliff, Ralph F. \\ Model, Sean M. \\ Mohlin, Peter J. \\ Nobre, Carlos A. \\ Olbers, Dirk J. \\ Paduan, Jeffrey D. \\ Phillips, William G. \\ Pierce, Therese M. Z. \\ Rasch, Philip J. \\ Reynolds, Peter G. \\ Richiardone, Renzo \\ Ridge, Daniel V.
}

Rivero, Juan
Robinson, Lisa M.
Schayes, Guy H.
Schlinkert, George A.
Serafino, George N.
Shaffer, Eugene H.
Sharp, John D.
Smart, John R.
Stephan, George F.
Sutker, Bradley D.
Thompson, Chris D.
Tipton, Sherree L.
Tongue, Jeffrey S.
Towne, David K.
Tung, Shu-Lin
Uchiyama, Akihiro
Wang, Dong-Ping
Warburton, John D.
Wendel, John M.
Wilson, James B.
Wiscombe, Warren J.

The Executive Committee has approved the election of the following candidates to the grade of Corporation Member.

E-Systems, Inc.

Israel, Embassy of, Defense and Armed Forces Attache

The Executive Committee has approved the election of the following candidates to the grade of Associate Member.

\author{
Alan, Robert W. \\ Britt, Mark F. \\ Bucher, Hugh A. \\ Carlson, Robert J. \\ Carpenter, Charles D. \\ Carreau, Daniel S. \\ Cheshire, Tanya K. \\ Churchill, Thomas J. \\ Craps, Mary R.
}

\author{
Dickson, David M. \\ Duncan, Robert E., Jr. \\ Elias, William E. \\ Ellis, Howard T. \\ Freischlag, William O. \\ Galvan, Roland J. \\ Graphos, George J. \\ Greenbrook, Reginald G. \\ Grossman, Barry R.
}

Gutsch, William A., Jr.

Hooper, Scott A.

Kahn, Philip H.

Leone, Richard A.

Maginnis, Karen M.-B.

McClung, Timothy W.

Moore, Gregory J.

Nickerson, Richard G. Noah, Dale G.
Perry, Keith E. Renner, Jeffrey B. Robinson, Sherryl D. Root, Timothy C. Smith, Richard D. Smith, William H. Streeto, Paul R. Swinford, Robert W. Timmerman, William L.

The Executive Committee has approved the election of the following candidates to the grade of Student Member.

\author{
Albert, Drew S. \\ Al-Zureiky, Saeed \\ Barger, David V. \\ Belasco, Scott J. \\ Bennett, Cheryl A. \\ Blakley, Pamela D. \\ Blanchard, Joe L., II \\ Brunet, Rene J., III \\ Buddeke, Ivo W. \\ Carlson, Catherine A. \\ Chen, Shu-Yi \\ Cimino, Christopher
}

Cunningham, Mark R.

Deola, Regina A.

Dignon, Nancy E.

Dorman, Jeffrey $\mathbf{L}$.

Dorris, Kevin S.

Eisenhower, Gerald M.

Flament, Pierre J.

Frey, Derek S.

Goswami, V. Kumar

Goulette, Ann M.

Graham, Nicholas E.

Johnstone, Susan A.
Kahl, Jonathan D.

Kleinerman, Joseph E.

Langland, Rolf $\mathrm{H}$.

Last, Jeffrey $\mathrm{K}$.

Lesniak, Karen M.

Lund, Donald E.

Majewski, Michael A.

McInnes, Kathleen L.

Miller, Mark A.

Miller, Roland J.

Mroz, John
Nesvacil, Kathy L. Neumann, Gary L. Noonan, Julie A. O'Handley, Chris Parker, Lindsay

Pearson, Gay

Perillo, Robert

Schroering, Don J.

Sindler, Rick K.

Trimborn, Richard J.

Walton, Grady G. 


\section{15/L78 $35 \mathrm{~A}-2 \quad 0034123231$ UC.}
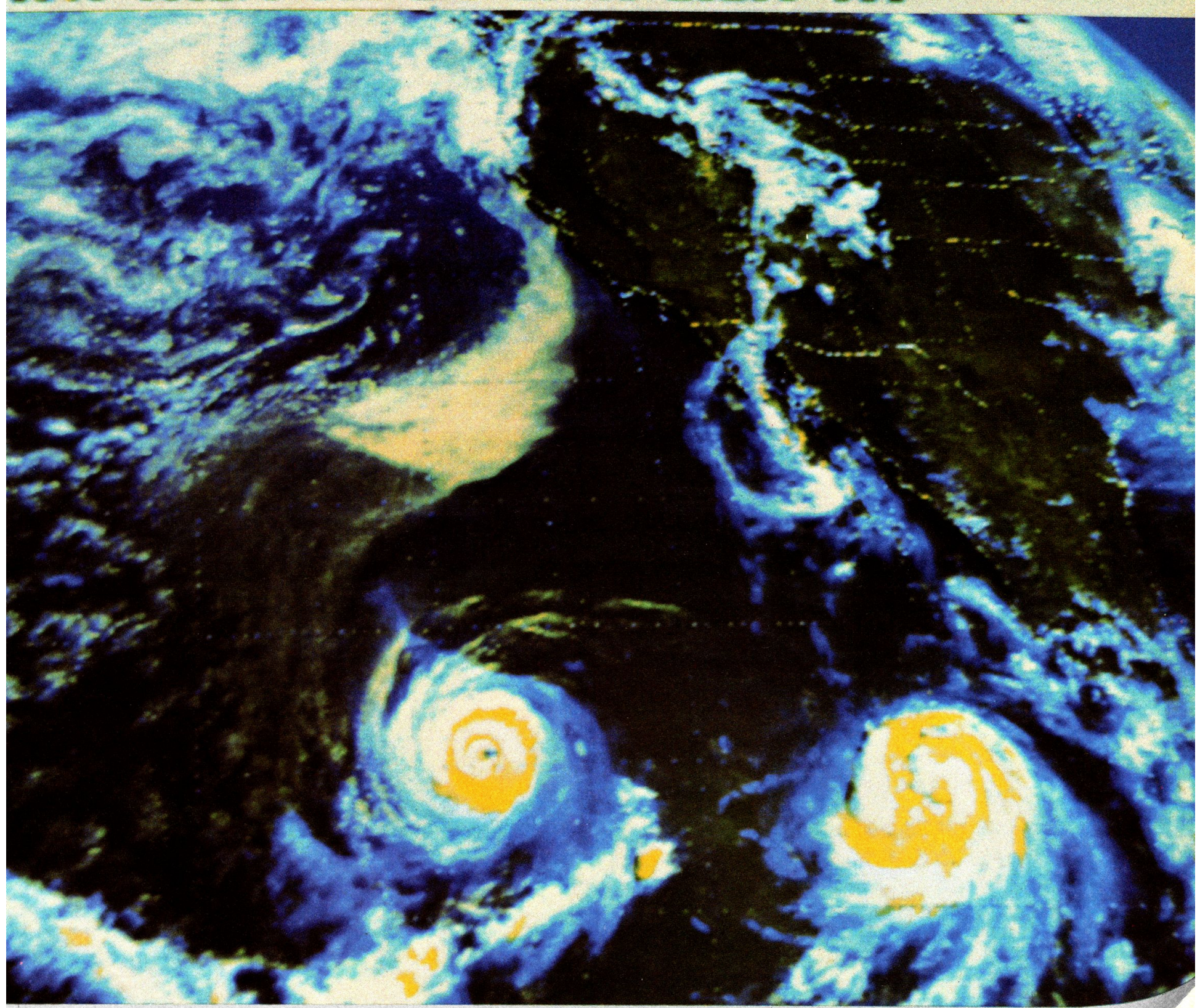

\section{Meteorology and Image Processing}

Atmospheric Analysis: 12S image processing techniques are helping meteorologists understand the complex processes and phenomena associated with the earth's atmosphere.

This image of two hurricanes off the coast of Central America derives from data transmitted by the "GOES WEST" satellite at an altitude of 34,000 kilometers. Winds in hurricane Fico at the left, exceeded 200 kilometers per hour, while those of sister hurricane Gilma reached 130 kilometers per hour.

Generated using an I2S System 575 workstation to combine the visible and near-infrared satellite

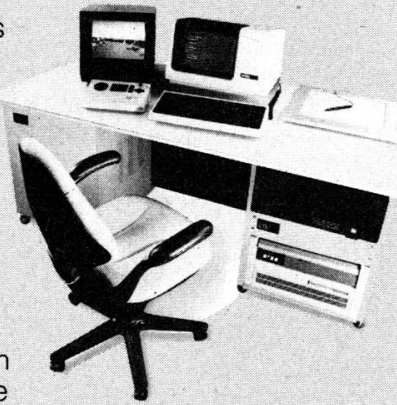
images, this color image represents one of the system's many image processing capabilities-capabilities that

extend to simulated three-dimensional fly-bys around entire hurricane systems. Learn more about the affordable, top-performing System 575-the total image processing solution from $12 \mathrm{~S}$.

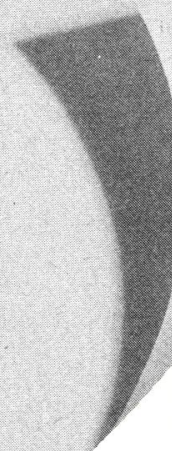

2
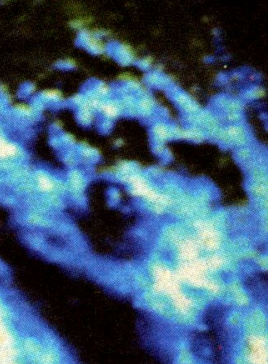


\section{INTRODUCING}

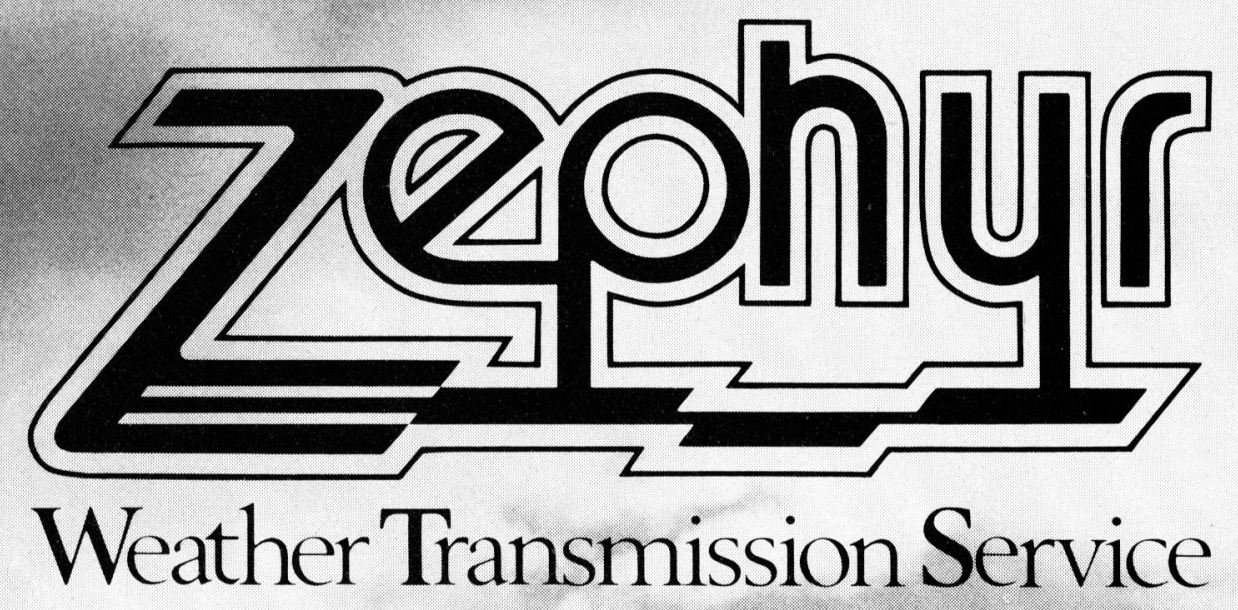

\section{Here's the best total weather information package you can have. And it's probably the least expensive.}

$\mathrm{Z}$

ephyr is the only satellite-transmitted delivers it all. Only Zephyr combines National Weather Service facsimile and text data with exclusive private information services. Whether you need all or part of this package - you will have the most cost-efficient weather information possible. Through United Video, the cable television industry's most experienced common carrier, Zephyr signals are uplinked to a communications satellite, and downlinked to a local satellite receiving system. All you need to receive Zephyr is a short local phone line to your office from the receiving point. No other receiving equipment is necessary.

You can't have more, or better information for less:

- A complete package of NWS Services to choose from plus new private services being developed.

- Short phone loops overcome the expense of long, inefficient land lines.

- And Zephyr provides "insurance" from the potential of increased costs or even eventual discontinuation of some government services.

While Zephyr didn't spring-up to make your job a breeze ... it will put some sunshine in your day! Mail this coupon today for full details. Or call United Video toll-free 1-800-331-4806 and ask for Zephyr.

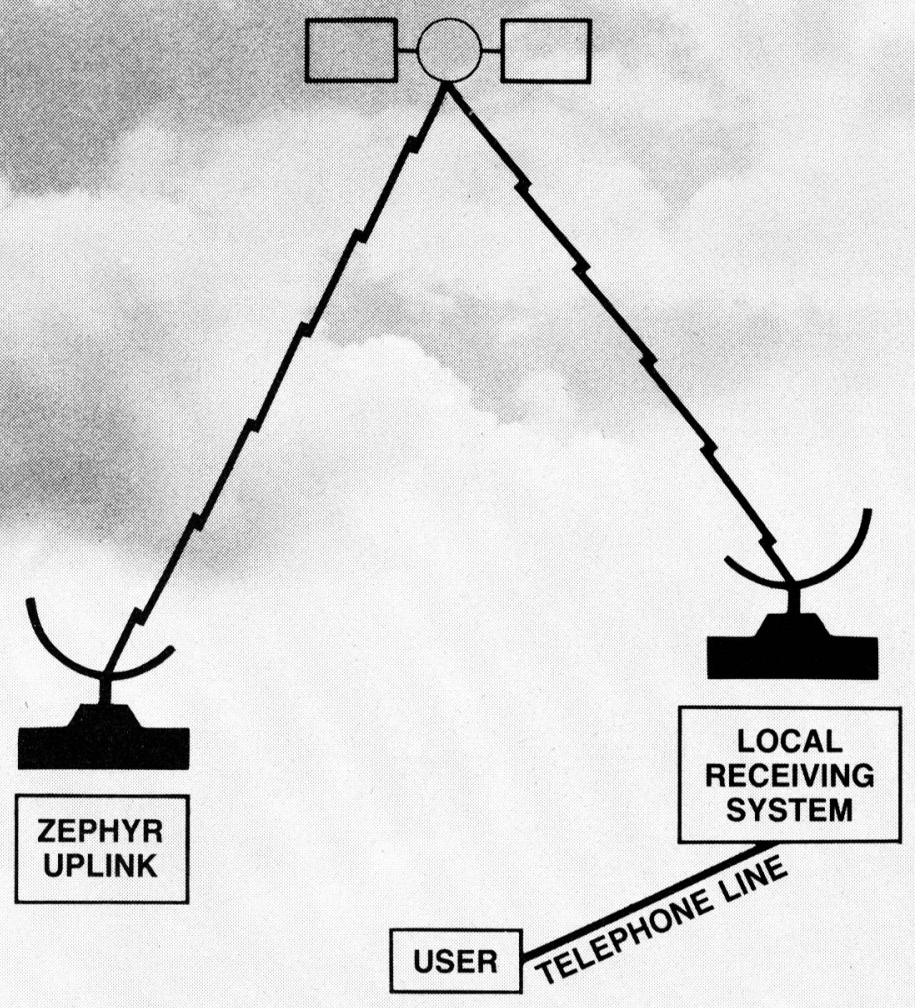

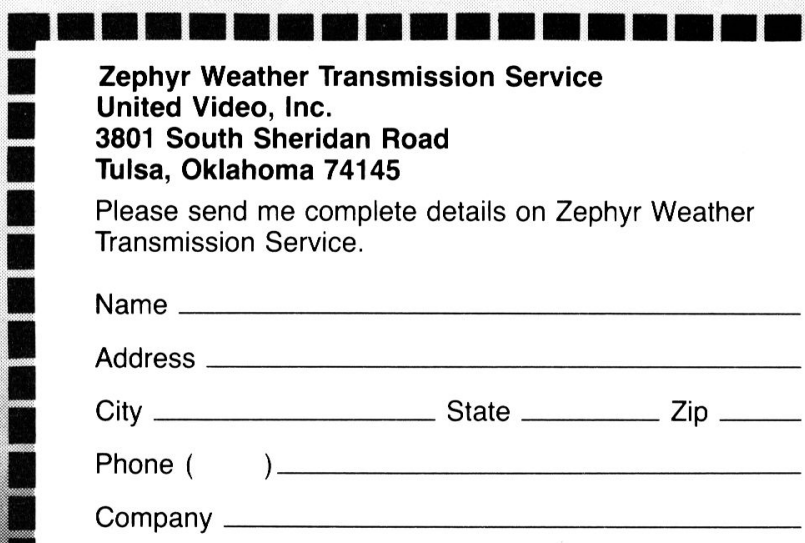

